Portland State University

PDXScholar

$4-1-2002$

\title{
Cross-cultural communication: implications for effective information services in academic libraries
}

Jian Wang

Portland State University, jian@pdx.edu

Donald G. Frank

Portland State University

Follow this and additional works at: https://pdxscholar.library.pdx.edu/ulib_fac

Part of the Library and Information Science Commons

Let us know how access to this document benefits you.

\section{Citation Details}

Wang, J., \& Frank, D. (2002). Cross-cultural communication: implications for effective information services in academic libraries. Portal: Libraries \& The Academy, 2(2), 207-216.

This Article is brought to you for free and open access. It has been accepted for inclusion in Library Faculty Publications and Presentations by an authorized administrator of PDXScholar. Please contact us if we can make this document more accessible: pdxscholar@pdx.edu. 


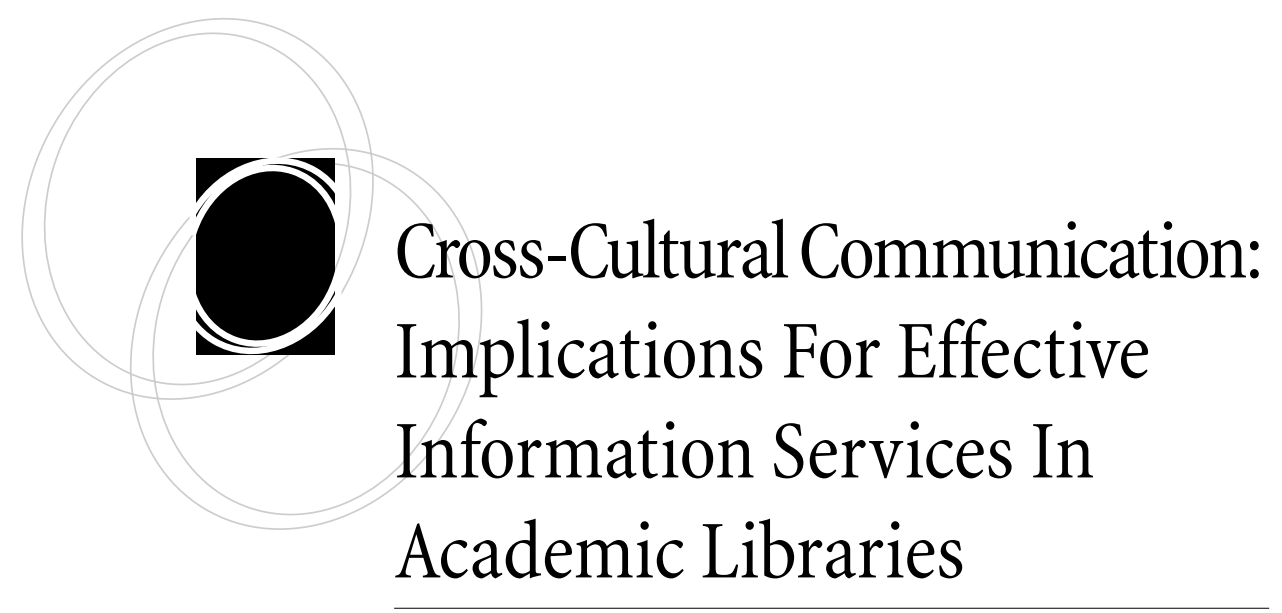

Jian Wang and Donald G. Frank

abstract:International students and scholars on campuses in the United States constitute a complex, diverse, and rapidly growing population that must be served effectively by academic libraries. This article examines cultural differences with a focus on communication processes and styles, and recommends ways to accommodate cross-cultural differences in information services. The article includes a survey of relevant literature and draws on the results of a series of focus groups conducted at Harvard University, the Georgia Institute of Technology, Portland State University, and one of the annual conferences of the American Library Association.

$\mathrm{T}$

he number of international students attending colleges and universities in the United States has been increasing dramatically for several decades. In the 195455 academic year, 34,232 international students were enrolled in American colleges and universities. ${ }^{1}$ By the 1999-2000 academic year, 514,723 international students were enrolled. This is a total increase of 1,411 percent, and is an average annual increase of 31 percent. Of the various international student subgroups, Asians currently represent about 58 percent of the total. Data for the larger subgroups include: China $(54,466$ students), Japan $(46,872)$, InThe positive contributions of international students to academe's intellectual and social processes are numerous. dia $(42,337)$, Korea $(41,191)$, Taiwan $(29,232)$, Canada (23,544), Indonesia (11,300), Thailand (10,983), Mexico (10,607), and Turkey $(10,100)$. Popular areas of study for international students in the United States are business and management ( 20 percent) and mathematics and computer science (19 percent). ${ }^{2}$ 
The positive contributions of international students to academe's intellectual and social processes are numerous. They contribute significantly to the success and enrichment of colleges and universities. International students typically represent the best of their nations' intellectual life. They usually come to the United States with solid to superior academic credentials and contribute significantly to academic excellence on campuses. Their presence tends to enrich campus diversity by exposing other graduate and undergraduate students to different cultural and ethnic experiences. Their presence also promotes a degree of global awareness on campus. ${ }^{3}$

From an economic perspective, international students in private and state-supported institutions typically pay some form of full-fare international tuition (similar to out-ofstate tuition), thereby contributing more, from a per student basis, to the institution's overall budget. They frequently seek and accept on-campus jobs as research or teaching assistants partially to defray expenses, providing a pool of researchers and teachers at lower cost to the institution. ${ }^{4}$

International students who study and are trained in U.S. business or management schools are more likely to have a better understanding of American business behaviors and practices, potentially influencing and facilitating business transactions in the global market. These students are also, to some degree, influenced by the social and intellectual customs and practices of other students and professors, promoting an increased understanding of the people of the United States. ${ }^{5}$

As the number and diversity of international students continue to grow on campuses, the need to understand and to work effectively with this population becomes more important for academic librarians who are responsible for providing effective information services to all students.

\section{Underutilization of Information Services}

Effective academic libraries are integrated into the instructional and research fabric of their institutions. All are concerned with the students on their campuses and, increasingly, with students at other locations via distance programs. Nonetheless, more attention needs to be focused on the information-seeking behaviors, practices, and interests of international students as well as on these students' perceptions of libraries and available information services. Data from a series of focus groups indicate that international students may not be fully aware of the readily available professional assistance on information-related issues. As a result, international students tend to underuse available information services. ${ }^{6}$ Several factors contribute to this underutilization.

International students tend to be unfamiliar with the organization and mission of academic libraries in the United States. Libraries in their countries are organized differently, with missions and strategic goals that are occasionally dramatically different. Reference and information services are not necessarily available for all students. Access to books and other forms of information may be limited. Databases may or may not be available and accessible. Card catalogs and closed stacks are still used in some libraries or information centers. These are significant differences. ${ }^{7}$

International students may not be as skilled with the various information technologies that are understood and used routinely by others. Some feel intimidated by 
these technologies, but do not ask for professional assistance. Other students have not used computers or have used computers on a limited basis. Some do not know how to type and struggle with computer keyboards. ${ }^{8}$

International students may not ask for assistance. International students are occasionally hesitant to approach reference stations and professional librarians as a result of communication differences or difficulties, preconceptions of cultural differences, and other reasons. Some are simply scared and lack the confidence needed to ask for assistance with information-related issues. ${ }^{9}$

International students may not be information-literate nor skilled in the ability to seek, to obtain, and to evaluate information. They frequently rely on the informal comments and suggestions of other students. While this phenomenon is not limited to international students, it is relevant to their information needs and realities. International students need to be included in the academic library's ongoing information literacy program. ${ }^{10}$

This underutilization of information services emphasizes the need to reassess the academic library's programs and services and make them more culturally responsive. Academic librarians need to be challenged continually to integrate cross-cultural differences into information services so that libraries are able to respond effectively to the information needs of international students and scholars.

\section{Culture and Cultural Differences}

To understand fully the needs and interests of international students, it is important to be familiar with key differences and similarities of the various cultures and histories represented by these students. Additionally, international students interact and communicate with others within the context of inter- and intra-cultural environments. Some familiarity with this context facilitates a deeper understanding of the international student.

Cultures of people (nations) and organizations are complex and diverse. There are individual, organizational, and national cultures. Edgar H. Schein's classic studies of organizational cultures are relevant. He defines organizational culture as the "pattern of basic assumptions that a given group has invented, discovered, or developed in learning to cope with its problems of external adaptation and internal integration, and that have worked well enough to be considered valid, and, therefore, to be taught to new members as the correct way to perceive, think, and feel in relation to those problems." ${ }^{11}$ He also stresses the importance of being aware of the underlying assumptions that shape and influence cultures. Academic libraries are organizations that exist within the context of specific cultures that are shaped and, to a degree, governed by various underlying assumptions. Libraries and librarians develop and implement services that are influenced by specific assumptions that are culturally and intellectually based.

Cultures are also characterized by shared values, including the basic assumptions that influence these values. ${ }^{12}$ Additionally, cultures are defined by "collective characteristics," with both tangible and intangible attributes. Individuals in the culture or group will occasionally differ or vary on the cultural continuum, but the overall group tends to be harmonious as a collective entity. ${ }^{13}$ Basically, a culture or community shares a set 
of common experiences and values that shape perceptions of other cultures or communities, including academic libraries. Simply stated, "culture is central to what we see, how we make sense of what we see, and how we express ourselves."14

So, one's culture affects attitudes, behaviors, practices, and values. One's sense of what is ethical, unethical, good, bad, appropriate, or inappropriate is influenced dramatically by one's culture. Attitudes toward life, work, or family will vary from one culture to another. Specific cultures determine or influence physical proximity in conversations with others, the ability to make direct eye contact in conversations, how we express feelings of happiness or frustration, and other basic behaviors/practices.

Progressing toward a fundamental understanding of these cultural differences is likely to minimize the misinterpretations and misunderstandings that occasionally affect cross-cultural communications. For example, Asian students are occasionally viewed or perceived as more reserved

\section{Information services in libraries that are sensitive to and encompass differences in culturally influenced communication styles are more likely to be responsive to the information needs and interests of international students.}

or non-assertive. "These [Asian] cultures place an emphasis on harmony and respect for authorities. Therefore, many of them are reluctant to share their feelings or emotions, express their opinions or oppositions to anyone, especially to authority figures. Thus instead of emphasizing personal rights and assertive communication, Asians tend to emphasize the importance of patience, harmony, respect, and deference. ${ }^{\prime 15}$ Information services in libraries that are sensitive to and encompass differences in culturally influenced communication styles are more likely to be responsive to the information needs and interests of international students.

Academic librarians are working and collaborating with students from different cultures. These students view librarians from differing perspectives that are shaped and influenced by fundamental cultural differences. As information professionals become more aware of the various cultural differences as well as the relative impact of these differences on cross-cultural communications, they become more effective listeners and communicators, able to empathize and understand. Information services become more responsive to the needs of international students.

\section{Unique Concerns of International Students and Scholars}

In spite of their cultural differences, international students generally share common problems, including language barriers, performance anxieties, loneliness and homesickness, and financial difficulties. They are challenged constantly to adjust to new academic and social conditions and environments. "Exposure to an unfamiliar environment can create anxiety, confusion, and depression. These conditions can lead to problems such as nervousness, loneliness, insomnia, and physical illness, all of which appear to interfere with their studies." ${ }^{\prime 16}$ 
Language barriers constitute a significant problem for international students. While international students are required to pass the Test of English as a Foreign Language (TOEFL) or other equivalent English proficiency examinations before coming to the United States, some may not realize fully that they speak English with an accent that is occasionally unintelligible to others. Also, some may be unaware that they use expressions that are not easily understood. Language barriers create communication problems, affecting the students' ability to communicate effectively with academic librarians and others in academe. Students become frustrated, which affects their ability to succeed.

International students are likely to experience some degree of "culture shock" in their initial year of adjusting to life and studies in a new environment. The psychological and physical stresses arising from cultural differences and from the pressures to adjust to or to conform to an unfamiliar culture can be overwhelming. Students need support and counsel to function competently. Academic librarians can be important advisors and counselors, helping international students obtain needed value-added information and to succeed academically.

\section{Different Communication Styles}

Communication is vital to personal and professional success. We communicate as we discuss or share ideas, express feelings, learn and grow as humans, and seek assistance or information. The way we communicate is influenced by culture. Being aware of cultural differences and communication styles helps us to understand the needs and motivations of students from different cultures and also helps to minimize misunderstanding. The following examples emphasize the need to be aware of differing styles of communication.

\section{Use of Language:}

One of the obvious barriers in cross-cultural communication is the use of language. Language reflects culture and tends to control or influence processes used to think and to perceive. For example, in focus groups at a major university, several Chinese students hesitantly stated that they were somewhat confused by the use of "Check Out Books" on a sign. For this group of students, "check out" implied "examining or searching." They were not interested in being examined or searched. In another focus group, the students stated that "checking out books" was associated with "paying for books." The librarians listened actively to the students and changed "Check Out Books" to "Borrow Books."17

\section{Nonverbal Communication:}

Verbal language is not the only mode of communication. Approximately 70 percent of communication is conveyed via non-verbal techniques. ${ }^{18}$ Facial expressions, physical gestures, posture, eye contact, and voice pitch or volume constitute important elements of nonverbal communication. Different cultures view or use these nonverbal elements differently. For example, American students tend to use eye contact in one-to-one con- 
versations, indicating interest and respect. Students from other cultures who look away in conversations with American students or librarians erroneously may be perceived as disrespectful or simply not willing to pay attention. Space is a factor in some cultures. Middle Eastern students, for example, tend to be physically closer to their conversational partners, indicating degrees of interest and collegiality. Japanese students tend to maintain some physical distance in conversations, emphasizing respect for others. Elements of posture are also considered to be more relevant by some cultures. Chinese students, for example, may correlate "correct posture" with respect for others. Sitting with one leg crossed over the other leg may be viewed as offensive by some Middle Eastern students. ${ }^{19}$

\section{Directness vs. Indirectness:}

Some international students from Asian nations are particularly sensitive to the need to "save face." If one is providing assistance or instruction for an Asian student and asks if the student understands, it is likely that the student will state that he or she does understand, even if the student fails to understand or is unsure. The student does not want to "lose face," and also does not want the instructor or librarian to "lose face." A response indicating that the student does not understand may reflect negatively on the student and on the instructor. In contrast, directness and assertiveness in communications are generally valued by American students and scholars. It is important for academic librarians to be sensitive to these different culturally-based approaches. ${ }^{20}$

\section{English Idioms:}

Idioms add a sense of vitality and color to the language and are used regularly by native speakers. Unfortunately, international students occasionally struggle to comprehend the context and meaning of idioms in conversations. An international student is likely to be misled by "Give me a ring," for example, especially if "Call me" is more accurate and appropriate. Use of plain and simple English in conversations with international students will help to minimize misunderstandings.

\section{Recommendations}

The following recommendations are intended to assist academic librarians in efforts to provide effective information services for international students. They are reminders to consider different cultures as programs and services are developed and implemented.

- Conduct "open houses" for international students, especially for the international students who are new on the campus. These provide informal opportunities for international students to meet librarians and to be exposed to some of the services provided by the academic library. In particular, the open houses provide opportunities to develop connections or partnerships. These are particularly relevant to the academic success of international students.

- Organize formal orientation programs that focus on the unique issues, needs, and concerns of international students. Emphasize the reality that the people who work in libraries are accessible, willing to listen actively, and qualified to assist. 
- Discuss the issues and concerns related to international students regularly. As information programs and services are developed and modified, integrate an "international student module" into these programs and services so that the needs of these students are included.

- Integrate the needs of international students into formal programs of information literacy. Librarians are involved actively in issues of teaching and learning on campuses. As we collaborate with faculty to create meaningful learning experiences for students, include the perspective of international students. For example, "challenging" students to learn via a particular class initiative may not be a positive experience for some international students. Consider all students as learning experiences are designed.

- Provide more assistance for new international students. The initial year for any student can be traumatic. This assistance can be integrated into a program that focuses on all new students.

- Cooperate with other units on the campus to facilitate success for international students. For example, communicate with units such as the "International Students Center" and the "Counseling Center."

- Become more familiar with the learning styles of international students by adjusting or tailoring instructional content to specific groups of librarians create more meaningful learning experiences. Research on the learning styles of international students indicates that they are generally goal-oriented and prefer informal one-toone relationships with in structors. They also prefer learning situations that provide direct contact with topics and materials.

Research on the learning styles of international students indicates that they are generally goal-oriented and prefer informal one-to-one relationships with instructors.

While these conditions will vary from group to group, it is important to learn more about these different learning styles. ${ }^{21}$

- Develop and conduct sensitivity training for librarians and staff who interact regularly with international students. Focus on the sensitive nature of cross-cultural communication, recognizing that cultural differences exist. It is important for international students (and indeed, all students) to feel as comfortable as possible in information-related situations. It is also important to accommodate different communication styles.

- Develop brochures or guides that provide information on programs and services in several languages. Examine existing signage to be sure that words or phrases are not potentially offensive or confusing to some international students.

- Active and sensitive listening is important. Additionally, body language can invite or impede questions from international students.

- Recruit and hire librarians and staff who come from different cultures. This provides opportunities for existing librarians and staff to learn and to become more 
sensitive to the needs of the various cultures. Additionally, international students will feel more comfortable as they see and interact with a diverse staff in academic libraries.

- Effective information services for international students as well as other specific groups need to be integrated into the library's mission statement. These services need to be included as strategic goals or options.

- Provide customized assistance or instruction on the use of electronic databases for international students. "International students' technological and computational experience should not be taken for granted. There ought to be a planned induction for international students into this electronic world." ${ }^{22}$ While electronic reference services are used increasingly by students, some international students may be reluctant to use these services. "For students from cultures that are more personal in their communicative styles, the new technologies can be very threaening in deeply alienating ways." ${ }^{\prime 23}$

- Recognize that each international student is an individual, regardless of the student's specific culture. Generalizations applied to individuals as well as groups may lead to practices and policies that are not as inclusive or effective as desired. "We are all shaped by many, many factors—our ethnic background, our family, our education, our personalities-and are more complicated than any cultural norm could suggest." 24

As information professionals consider the unique characteristics and communication styles of international students (and basically of all students), policies and services will be more reflective of and responsive to different cultures and, as a result, more effective.

\section{Concluding Comments}

Communicating across cultures is essential and should be a priority for academic librarians who are providing information services for international students. Other relevant articles on international students in the literature of academic librarianship do not necessarily focus on issues of communication and cross-cultural communication. They provide information and perspective on issues such as orientation methodologies, information-seeking behaviors and practices, usage patterns and trends, and assistance on dissertations. ${ }^{25}$ If the ability to communicate effectively within and across cultures is a priority in academic libraries, international students are more likely to succeed as information seekers and users, completing dissertations, theses, and other educational requirements.

More research on the issues related to communicating with international students in academic libraries is needed. As we confer with international students and become more familiar with the realities that underscore different cultures and communication styles, we will be able to integrate innovative ideas and perspectives into evolving information programs and services.

The relevance of academic libraries depends on the ability of the librarians to become integrated effectively into the instructional and research fabric of the college or university. If the librarians are integrated into the institutional fabric, the information 
services provided by the academic library are likely to be used and to be relevant to the needs of students and scholars. International students constitute an increasingly significant "body" on campuses. Academic librarians must be able to identify and work with the unique information-related issues associated with international students. If librarians fail to do so, the students will turn to other sources of information and other information providers.

Effective information services are customized and personalized to the specific needs of students, scholars, and administrators. The specific needs of international students must be included in this customized "mix" of services. International students add a special social and intellectual vitality to our campuses. As we work and collaborate with these students, providing assistance, counsel, and value-added information, we learn and grow as librarians and, in the process, our libraries become more relevant.

Jian Wang is the Serials Catalog Librarian for Millar Library at Portland State University; she may be contacted via e-mail at: jianw@pdx.edu.

Donald G. Frank is the Assistant Director for Public Services for Millar Library at Portland State University; he may be contacted via e-mail at: frankd@pdx.edu.

\section{Notes}

1. David A. Walker, "The International Student Population: Past and Present Demographic Trends," Journal of Instructional Psychology 27 (June 2000): 77.

2. Institute of International Education, "International Students on U.S. Campuses Top Half a Million: Enrollment Rises by 5\% With Strong Increases from China and India" (November 13, 2000). Available: <http://www.iie.org/svcs/pressrel/pr111300f.htm> [February 11, 2002].

3. Chuck Tomkovick, et al, "An Assessment of the Service Quality Provided to Foreign Students at U.S. Business Schools," Journal of Education for Business 61 (January-February 1996): 130 .

4. Ibid., 130 .

5. Ibid.

6. For example, see Daniel Liestman, "Reference Services and the International Adult Learner," The Reference Librarian 69/70 (2000): 363-378. Or, Calmer D. Chattoo, "Reference Services: Meeting the Needs of International Adult Learners," The Reference Librarian 69/70 (2000): 349-362. Also, these themes were illustrated in randomly selected focus groups of international students and reference librarians at Harvard University (1994), the Georgia Institute of Technology (1998), Portland State University's Center for Academic Excellence (2000), and the American Library Association's Annual Conference (2001).

7. Suhasini L. Kumar and Raghini S. Suresh, "Strategies for Providing Effective Reference Services for International Adults Learners," Reference Services for the Adult Learner 69/70 (2000): 327-336. These themes were also illustrated in the randomly selected focus groups of international students and reference librarians at Harvard University (1994), the Georgia Institute of Technology (1998), Portland State University's Center for Academic Excellence (2000, and the American Library Association's Annual Conference (2001).

8. Sidney R. Grant, “The Internationalizing Influences of New Communication Technologies," New Directions for Student Services 86 (Summer 1999): 59-65.

9. See Dania M. Bilal, "International Students' Acquisition of Library Research Skills: Relationship With Their English Language Proficiency," Reference Librarian 24 (1989): 129_ 145. Also see Daniel Liestman, "Reference Services and the International Adult Learner," The Reference Librarian 69/70 (2000): 363-378. 
10. Reliance on and use of the informal comments and suggestions of immediate colleagues were themes expressed in the randomly selected focus groups of international students and reference librarians at Harvard University (1994), the Georgia Institute of Technology (1998), Portland State University's Center for Academic Excellence (2000), and the American Library Association's Annual Conference (2001).

11. Edgar H. Schein, "Coming to a New Awareness of Organizational Culture," Sloan Management Review 25 (Winter 1984): 3-4.

12. Stephan Dahl, "Communications and Culture Transformation" (2000). Available: <http:// www.stephweb.com/capstone/capstone.shtml> [February 11, 2002].

13. Tomasz Lenartowicz and Kendall Roth, "A Framework for Culture Assessment," Journal of International Business Studies 30 (4): 798.

14. Marcelle E. DuPraw and Marya Axner, "Working on Common Cross-Cultural Communication Challenges" (1997). Available:< http:/ /www.pbs.org/ampu/ crosscult.html> [February 11, 2002].

15. Jun-Chih Gisela Lin and Jenny K. Yi, “Asian International Students' Adjustment: Issues and Program Suggestions," College Student Journal 31 (December 1997): 476.

16. Ibid., 474 .

17. Focus groups conducted at the Georgia Institute of Technology (1998).

18. Annetta Lopaz, "Did I See You Do What I Think You Did? The Pitfalls of Nonverbal Communication Across Cultures," New Jersey Libraries (Winter 1993/94): 19.

19. Roger E. Axtell, Gestures: The Do's and Taboos of Body Language Around the World (New York: Wiley, 1991), 131-231.

20. See, for example, "Take a Cross-Cultural Communication Quiz" (2000). Available: <http:// www.gmac.com/services/prof_dev/regional_workshops/quiz.shtml> [February 11, 2002]. Issues of directness and indirectness in communications were also reflected in the focus groups at Harvard University (1994), the Georgia Institute of Technology (1998), Portland State University's Center for Academic Excellence (2000), and the American Library Association's Annual Conference (2001).

21. Paula D. Ladd and Ralph Ruby, "Learning Style and Adjustment Issues of International Students," Journal of Education for Business 74 (July/August 1999): 365.

22. Sidney R. Grant, "The Internationalizing Influences of New Communication Technologies," New Directions for Student Services 86 (Summer 1999): 65.

23. Ibid., 65.

24. DuPraw and Axner, "Working on Common Cross-Cultural Communication Challenges," <http://www.pbs.org/ampu/crosscult.html> [February 11, 2002].

25. See, for example, May Ying Chau and Michael Culbertson, "Library Services for International Students: A Study at Colorado State University," Colorado Libraries 20 (Fall 1994): 40-41; Allen Natowitz, "International Students in U.S. Academic Libraries: Recent Concerns and Trends," Research Strategies 13 (Winter 1995): 4-16; Kwasi Sarkodie-Mensah, "International Students in the U.S.: Trends, Cultural Adjustments, and Solutions for a Better Experience," Journal of Education for Library and Information Science 39 (Summer 1998): 214-222; Mary Beth Allen, "International Students in Academic Libraries: A User Survey," College E Research Libraries 54 (July 1993): 323-333; Dania M. Bilal, "International Students' Acquisition of Library Research Skills: Relationship With Their English Language Proficiency," Reference Librarian 24 (1989): 129-145; Yvonne de Souza, "Reference Work with International Students: Making the Most Use of the Neutral Question," Reference Services Review 24 (1996): 41-48. 